\title{
UTILITY-BASED ROAD MAINTENANCE PRIORITIZATION METHOD USING PAVEMENT OVERALL CONDITION RATING
}

\author{
SALEH ABU DABOUS ${ }^{1 *}$, GHADEER AL-KHAYYAT ${ }^{2}$, \\ SAINAB FEROZ ${ }^{3}$ \\ ${ }^{1,3}$ Department of Civil and Environmental Engineering, \\ Sustainable Civil Infrastructure Research Group, Research Institute of Sciences \\ and Engineering, University of Sharjah, Sharjah, UAE. \\ ${ }^{2}$ GIS Consultant, Experts Computer Consultancies Est. (ECCE), Dubai, UAE
}

Received 21 April 2019; accepted 29 October 2019

\begin{abstract}
Pavement maintenance and rehabilitation are expensive activities and the available budget to manage the existing pavement infrastructure is limited. Managers require a prioritization method to assist them in selecting the most appropriate maintenance options. Maintenance prioritization is necessary to maintain pavement sections at acceptable service levels within the given budget and resource constraints. In this paper, a utility approach is proposed for maintenance prioritization purposes based on the condition assessment results of the pavement sections. A pavement network of five sections is considered in this study, and a numerical example is illustrated considering one section to show the implementation of the utility approach for section ranking. The overall assessment of various pavement sections was provided by the inspector as degrees of belief in seven assessment grades, which are: A
\end{abstract}

* Corresponding author. E-mail: sabudabous@sharjah.ac.ae

Saleh ABU DABOUS (ORCID iD 0000-0002-8777-2331)

Ghadeer AL-KHAYYAT (ORCID iD 0000-0002-7592-4561)

Sainab FEROZ (ORCID iD 0000-0002-2796-1552)

Copyright (C) 2020 The Author(s). Published by RTU Press

This is an Open Access article distributed under the terms of the Creative Commons Attribution License (http://creativecommons.org/licenses/by/4.0/), which permits unrestricted use,

distribution, and reproduction in any medium, provided the original author and source are credited. 
(Good), B (Satisfactory), C (Fair), D (Poor), E (Very poor), and F (Serious). The assessment of pavement condition and the estimated grade utilities are used to calculate maximum, minimum, and average utilities for each of the five pavement sections. Based on the results, the pavement sections are ranked for maintenance and rehabilitation actions.

Keywords: decision, distress, maintenance, pavement, road, utility.

\section{Introduction}

A well-maintained highway network is a reflection on any nation's economic growth. With the ever-increasing cost of materials, engineers are in constant search for simpler and cheaper ways to manage and maintain pavements at an acceptable service level. Pavement management system (PMS) has proven to be efficient and cost-effective in this endeavour.

Pavement management includes planning, design, construction, maintenance, and rehabilitation of pavements. PMS is a planning tool that aids decision-makers provide optimal solutions for maintaining pavements at the desired levels. PMS helps rate pavements as good, fair, or poor and regulate maintenance and repairs to ensure the pavement remains in a good state. PMS, in addition to enhancing the efficiency of decision-making, gives feedback on the outcomes of decisions and ensures that there is consistency and coordination of activities and decisions within the organization (Haas, Hudson, \& Zaniewski, 1994; Hudson, Haas, \& Pedigo, 1979). While developing a PMS, a pavement condition assessment (PCA) method is considered one of the essential elements needed for the appropriate functioning of the PMS, as condition assessment is directly linked to safety, serviceability, and sustainability of the managed pavement infrastructure. Pavement decline in a highway network can be quantitatively measured using PCA (Chouinard, Andersen, \& Torrey, 1996; Haas et al., 1994; Sun \& Gu, 2011).

All pavements deteriorate over time. The first signs appear as minor distresses which escalate to significant damage as the pavement ages. Distressed pavement results from various factors, such as environment, traffic, material properties, quality of road construction, design standards and the age of the pavement, rather than just one root cause. These distresses are manifested as cracking, surface and subsurface deformations, disintegration and surface defects (Temesgen Girmay, 2016). Maintenance and rehabilitation are two primary treatment techniques used to enhance pavement condition. Maintenance techniques work by retarding the rate of decline of the pavement by repairing small defects before they aggravate to create larger defects. However, these techniques work only until a certain point. Rehabilitation
Utility-Based

Road Maintenance

Prioritization Method

Using Pavement

Overall Condition

Rating 
techniques can be used to enhance pavement condition by rectifying the relatively severe defects.

In this paper, final degrees of belief in each assessment grade for five pavement sections were extracted from a database based on inspector judgement. Then, utility equations were applied on the pavement sections for maintenance prioritization ranking purposes. The study introduces the utility principle to road maintenance management as a novel approach to rank and prioritize pavement sections for intervention. Condition rating of the pavement sections estimated based on the theory of evidence forms the basis of utility ranking. The proposed method is demonstrated with a case study that includes detailed calculations of utilizing utility equations in pavement ranking based on their overall condition rating.

\section{Background information on pavement prioritization techniques}

Pavement maintenance and rehabilitation can be very expensive. Decision-makers often face dilemmas in determining which pavement sections require mending, what treatment techniques are to be carried out, and when and how to schedule these repairs. To restore the pavements to acceptable service levels within the given budget and resource constraints, maintenance prioritization is necessary. There are various project prioritization techniques.

- Selection Based on Ranking: this method is carried out by rating alternatives based on an indicator. This indicator depends on the analysts' judgement, pavement condition, or economic analysis (Torres-machí, Chamorro, Videla, Pellicer, \& Yepes, 2014). In order to determine the indicators based on judgement, an expert panel performs the ranking of alternatives. This method was applied on a road network in India using traffic, connectivity, and road and drainage conditions as the factors (Shah, Jain, \& Parida, 2014). When assessment is based on pavement condition, a Single or a Composite Condition Index is used to rank pavement sections. Reddy \& Veeraragavan (2001) used a Composite Condition Index based on pavement surface distresses, traffic information, and expert opinion to determine the priority of 52 sections. The benefit of using ranking based on economic analysis is that it considers the cost of various sections. A sequential method was adopted by Shah et al., (2014) to demonstrate this approach.

- Mathematical Optimization Methods: these methods focus on selecting alternatives maximizing or minimizing an objective 
function with regard to some criterion. The methods often used in pavement management are linear, nonlinear, integer, and dynamic programming (Torres-machí et al., 2014).

- Near Optimization or Heuristic Methods: these methods provide close approximations to the values obtained from mathematical optimization, searching for better solutions within the constraints, using incremental benefit/cost analysis, local search heuristics, and evolutionary algorithms.

- Other optimization methods include Neural Networks and Fuzzy Logic. Neural networks generalize and generate decisions by learning from examples. They are able to imitate the decisionmaking capability of humans without the use of any predefined mathematical equations. Fwa and Chan (1993) successfully demonstrate the use of neural networks for determining the priority rating of highway pavements. On the other hand, fuzzy logic systems can manage numerical data and linguistic knowledge. They can integrate vague qualitative data into the decision-making process. Moazami et al. (2011) applied fuzzy logic to prioritize 131 pavement sections in Tehran using such factors as pavement condition index, traffic volume, road width, as well as rehabilitation and maintenance cost.

Several studies have implemented various pavement condition prioritization techniques, which are summarized in Table 1 , and inspected the efficiency of time-cost optimization based on genetic algorithms (GAs), fuzzy logical control, integer programming, and ant colony algorithms (El-rayes \& Kandil, 2005; Xiong \& Kuang, 2007; Zheng \& Ng, 2005; Zheng, Ng, \& Kumaraswamy, 2004). GAs and ParticleSwarm Optimization (PSO) demonstrate excellent results in pavement management analyses as well as in managing M\&R activities (Fwa, Chan, \& Hoque, 1998; Tayebi, Moghadasnejhad, \& Hassani, 2010).

\section{Utility approach to pavement maintenance prioritization}

Pavement sections are usually assessed by regular inspection routines. Based on extent and severity level of various distresses that are present in a pavement section, inspectors will evaluate the pavement section accordingly. Pavement inspection guidelines and procedures are provided in standard manuals of practice. These manuals typically utilize numeric indexes or linguistic expressions to define different possible condition states that an inspector can assign
Utility-Based

Road Maintenance

Prioritization Method

Using Pavement

Overall Condition Rating 
Table 1. Literature review on pavement maintenance prioritization methods

\begin{tabular}{|c|c|c|}
\hline Author & Literature & Technique Used \\
\hline Shah et al., 2014 & $\begin{array}{l}\text { Evaluation of prioritization methods for } \\
\text { effective pavement maintenance of urban } \\
\text { roads }\end{array}$ & $\begin{array}{l}\text { Selection based on Ranking: } \\
\text { Judgement and Economic } \\
\text { Analysis }\end{array}$ \\
\hline Reddy \& & Priority ranking model for managing & Selection based on Ranking: \\
\hline Veeraragavan, 2001 & flexible pavements at network level & Pavement Condition \\
\hline Fwa \& Chan, 1993 & $\begin{array}{l}\text { Priority rating of highway maintenance } \\
\text { needs by neural networks }\end{array}$ & Neural Networks \\
\hline Moazami et al., 2011 & $\begin{array}{l}\text { Pavement rehabilitation and maintenance } \\
\text { prioritization of urban roads using fuzzy } \\
\text { logic }\end{array}$ & Fuzzy Logic \\
\hline Zheng et al., 2004 & $\begin{array}{l}\text { Applying a genetic algorithm-based } \\
\text { multi-objective approach for time-cost } \\
\text { optimization }\end{array}$ & Genetic Algorithm \\
\hline Zheng \& Ng, 2005 & $\begin{array}{l}\text { Stochastic Time-Cost Optimization } \\
\text { Model incorporating fuzzy sets theory and } \\
\text { nonreplaceable front }\end{array}$ & $\begin{array}{l}\text { Fuzzy Sets Theory, } \\
\text { Nonreplaceable Front } \\
\text { Concept, Utility Theory, } \\
\text { Opportunity Cost, Genetic } \\
\text { Algorithm }\end{array}$ \\
\hline $\begin{array}{l}\text { El-rayes \& Kandil, } \\
2005\end{array}$ & $\begin{array}{l}\text { Time-cost-quality trade-off analysis for } \\
\text { highway construction }\end{array}$ & Genetic Algorithm \\
\hline Xiong \& Kuang, 2007 & $\begin{array}{l}\text { Time-cost trade-off of construction } \\
\text { project based on ant colony algorithm }\end{array}$ & $\begin{array}{l}\text { Ant Colony Optimization } \\
\text { Algorithms }\end{array}$ \\
\hline Fwa et al., 1998 & $\begin{array}{l}\text { Analysis of pavement management } \\
\text { activities programming by genetic } \\
\text { algorithms }\end{array}$ & Genetic Algorithm \\
\hline Tayebi et al., 2010 & $\begin{array}{l}\text { Analysis of pavement management } \\
\text { activities programming by particle swarm } \\
\text { optimization }\end{array}$ & $\begin{array}{l}\text { Particle Swarm Optimization } \\
\text { Method }\end{array}$ \\
\hline $\begin{array}{l}\text { Ouma, Opudo, \& } \\
\text { Nyambenya, } 2015\end{array}$ & $\begin{array}{l}\text { Comparison of Fuzzy AHP and Fuzzy } \\
\text { TOPSIS for road pavement maintenance } \\
\text { prioritization }\end{array}$ & Fuzzy AHP and Fuzzy TOPSIS \\
\hline $\begin{array}{l}\text { Gao, Xie, \& Zhang, } \\
2012\end{array}$ & $\begin{array}{l}\text { Network-level road pavement } \\
\text { maintenance and rehabilitation scheduling } \\
\text { for optimal performance improvement } \\
\text { and budget utilization. Computer-aided } \\
\text { civil and infrastructure engineering }\end{array}$ & Parametric Method \\
\hline Sun \& Gu, 2011 & $\begin{array}{l}\text { Pavement condition assessment using } \\
\text { fuzzy logic theory and analytic hierarchy } \\
\text { process. }\end{array}$ & Fuzzy Logic Theory and AHP \\
\hline
\end{tabular}




\begin{tabular}{lll}
\hline \multicolumn{1}{c}{ Author } & \multicolumn{1}{c}{ Literature } & \multicolumn{1}{c}{ Technique Used } \\
\hline $\begin{array}{l}\text { Babashamsi, } \\
\begin{array}{l}\text { Golzadfar, Yusoff, } \\
\text { Ceylan, \& Nor, 2016 }\end{array}\end{array}$ & $\begin{array}{l}\text { Integrated fuzzy analytic hierarchy process } \\
\text { and VIKOR method in the prioritization of } \\
\text { pavement maintenance activities }\end{array}$ & $\begin{array}{l}\text { Fuzzy AHP and VIKOR } \\
\text { Method }\end{array}$ \\
\hline & $\begin{array}{l}\text { Particle Swarm Optimization Method } \\
\text { for optimal prioritization of pavement } \\
\text { sections for maintenance and } \\
\text { rehabilitation activities }\end{array}$ & $\begin{array}{l}\text { Particle Swarm Optimization } \\
\text { Method }\end{array}$ \\
& & \\
\hline
\end{tabular}

to a pavement section. For example, ASTM D 6433 manual utilizes a rating system with pavement condition index values ranging from 0 to 100 distributed over seven assessment grades, which are Failed, Serious, Very poor, Poor, Fair, Satisfactory, and Good (ASTM, 2008). The Federal Highway Administration is another authority that developed a manual for pavement condition assessment with a grading system ranging from grade 1 to 10 with grade 1 representing the failed state and grade 10 representing the excellent state (The Ohio Department of Transportation and U.S. Department of Transportation, 1998). In this study, the basic probabilities of various assessment grades will be assigned by an inspector. If the assessment of the pavement section is complete, the total assessment will be equal to $100 \%$. On the other hand, if the assessment is not complete, the total assessment will not sum up to $100 \%$ and the remaining value will be considered as ignorance.

In practice, a large number of pavement sections need to be compared and prioritized based on their overall condition. To do so, a utility approach was used for maintenance prioritization. The data in Table 2 show the assessment grades utilized for pavement condition evaluation. The worse the pavement section condition is, the higher utility must be assigned to that section in order to be prioritized for maintenance. The

Table 2. Pavement condition assessment grades and their corresponding utilities

\begin{tabular}{ccc}
\hline Grade Assessment & Description & Utility \\
\hline A & Good & 0 \\
B & Satisfactory & 0.1 \\
C & Fair & 0.3 \\
D & Poor & 0.5 \\
E & Very poor & 0.7 \\
F & Serious & 0.9 \\
\hline
\end{tabular}


suggested utilities shown in Table 2 indicate that the best grade (A) takes the lowest utility of 0 and the worst grade (F) takes the highest utility of 0.9. Such utility arrangement will assign first rank to the pavement section with the worst overall condition assessment to be maintained first and the last rank - to the section with the best condition assessment to be maintained last.

\section{Road maintenance prioritization using the theory of evidence and utility model}

Prioritization of maintenance activities for a group of pavement sections needs a proper evaluation of the sections' overall condition. For that purpose, an analytical evidential reasoning (ER) approach can be used for overall condition assessment. The ER approach is based on the theory of evidence originally proposed by Dempster (1968) and finalized by Shafer (1976). Afterwards, the pavement sections can be ranked using the utility model. The advantages of the analytical ER approach in producing an overall assessment for the utility model are mainly using assessment grades for condition rating rather than numeric values, categorizing the distresses in the pavement section to more than one assessment grade by using probability assignment, providing an overall distributed assessment for the pavement section, and offering more flexibility while combining large number of distresses. The ER algorithm for multiple attribute decision analysis under uncertainty was proposed by Yang \& Xu (2002). The method proposed here assumes integration between the ER theory and the utility approach to the area of pavement maintenance management and evaluates the implementation using a case study.

The application of ER approach for condition assessment studies involves three main steps:

- Step 1: calculation of basic probability masses (Bpa);

- Step 2: aggregation of the basic probability masses; and

- Step 3: computation of the overall degrees of belief for various condition assessment grades (Abu Dabous \& Al-Khayyat, 2018; Abu Dabous, 2017; Wang \& Elhag, 2008; Wang, Yang, \& Xu, 2006).

The estimation of $B p a$ is an essential step in the ER approach; it is defined as the degree of belief or confidence in a frame of discernment. $B p a$ is usually denoted by letter m. Pavement inspectors and experts are asked to assign the $B p a$ values to various grades to a pavement section subjectively after reviewing the inspection reports.

The $B p a$ values are to be combined using ER combination rule to produce an overall condition rating. When considering the confidence 
associated with different assessment grades, pavement sections can be better evaluated in terms of their overall condition. Therefore, a distributed modelling framework for the selected distresses is produced and then an analytical ER algorithm needs to be developed to aggregate multiple distresses. The utilized frame of discernment contains $N$ assessment grades as follows: $H=\left\{H_{\text {Good }}, H_{\text {Satisfactory }}, \ldots, H_{N}\right\}$. The main concepts behind the application of the ER algorithm are summarized below.

1. The overall condition of $X$ pavement sections denoted by $P_{A}(A=1$, $2, \ldots, X)$ is to be assessed considering $Y$ factors denoted by $D_{B}(B=$ $1,2, \ldots, Y$ ). It is compulsory during the application of ER to satisfy that $\beta_{n, B}\left(P_{A}\right) \geq 0$ and $\sum_{n=1}^{N} \beta_{n, B}\left(P_{A}\right) \leq 1$, where $\beta$ indicates the degree of belief associated with each grade.

2. The belief decision matrix is represented by $\mathrm{D}=\left(\mathrm{S}\left(\mathrm{D}_{B}\left(P_{A}\right)\right)\right)_{Y X}$ for each pavement distress available in each pavement section, where $S$ represents the distributed assessments.

3. The aggregation of various assessment grades can be performed through recursive or analytical ER approach. The analytical ER is used in this study due to its flexibility compared to the recursive ER. The aggregation process includes the following steps.

- The degrees of belief of various distresses should be first converted to probability masses. Conversion is performed by combining the relative weights of the distresses and their degrees of belief using the following set of equations:

$$
\begin{gathered}
m_{n, B}=m_{B}\left(H_{n}\right)=w_{B}^{2}{ }_{n, B}\left(P_{A}\right), n=1, \ldots, N ; B=1, \ldots, Y ; \\
m_{H, B}=m_{B}(H)=1-\sum_{n=1}^{N} m_{n, B}=1-w_{B} \sum_{n=1}^{N} \beta_{n, B}\left(P_{A}\right), B=1, \ldots, Y ; \\
\bar{m}_{H, B}=\bar{m}_{B}(H)=1-w_{B}, B=1, \ldots, Y ; \\
\tilde{m}_{H, B}=\tilde{m}_{B}(H)=w_{B}\left(1-\sum_{n=1}^{N} \beta_{n, B}\left(P_{A}\right)\right), B=1, \ldots, Y ; \\
m_{H, B}=\bar{m}_{H, B}+\tilde{m}_{H, B} \text { and } \sum_{B=1}^{A} w_{B}=1,
\end{gathered}
$$

where $m_{n, B}$ represents the basic probability mass in each of the assessment grades of $P_{A}$ pavement section assessed to assessment grade $H_{n} ; m_{n, B}$ represents the basic probability mass assigned to the whole set $H$ and it consists of two parts: and, where is produced due to the relative importance of the pavement distresses and is caused by the incompleteness of assessment.
Utility-Based

Road Maintenance

Prioritization Method Using Pavement Overall Condition Rating 
- The basic probability masses are then aggregated though analytical ER approach using the following equations (Yang \& Xu, 2002):

$$
\begin{gathered}
\left\{H_{n}\right\}: m_{n}=k\left[\prod_{B=1}^{Y}\left(m_{n, B}+\bar{m}_{H, B}+\tilde{m}_{H, B}\right)-\prod_{B=1}^{Y}\left(\bar{m}_{H, B}+\tilde{m}_{H, B}\right)\right], n=1, \ldots, N ; \\
\{H\}: \tilde{m}_{H}=k\left[\prod_{B=1}^{Y}\left(\bar{m}_{H, B}+\tilde{m}_{H, B}\right)-\prod_{B=1}^{Y} \bar{m}_{H, B}\right] ; \\
\{H\}: \bar{m}_{H}=k\left[\prod_{B=1}^{Y} \bar{m}_{H, B}\right] ; \\
k=\left[\sum_{n=1}^{N} \prod_{B=1}^{Y}\left(m_{n, B}+\bar{m}_{H, B}+\tilde{m}_{H, B}\right)-(N-1) \prod_{B=1}^{Y}\left(\bar{m}_{H, B}+\tilde{m}_{H, B}\right)\right]^{-1} .
\end{gathered}
$$

- The aggregated probability assignments are finally to be normalized into overall belief degrees using the following equations (Yang \& Xu, 2002):

$$
\begin{gathered}
\left\{H_{n}\right\}: \beta_{n}=\frac{m_{n}}{1-\bar{m}_{H}}, n=1, \ldots, N ; \\
\{H\}: \beta_{H}=\frac{\tilde{m}_{H}}{1-\bar{m}_{H}},
\end{gathered}
$$

where $\beta_{n}$ and $\beta_{H}$ stand for the overall belief degrees assigned to assessment grades $H_{n}$ and $H$, respectively.

When basic assessment is incomplete, the likelihood that the pavement section $y$ may be assessed as $H_{n}$ can be any value in the interval $\left[\beta_{n}, \beta_{n}+\beta_{H}\right]$. In this case, three measures of utility that can be used to define the priority of section $p$ are the minimum, maximum and average expected utilities. Eq. (12) below estimates utility assigned to any pavement section $p$ and Eqs. (13)-(15) provide the maximum, minimum and average measures of utility that can be used in prioritization analysis (Yang \& $\mathrm{Xu}, 2002$ ).

$$
\begin{gathered}
u(p)=\sum_{n=1}^{N} \beta_{n} u\left(H_{n}\right), \\
u_{\text {max }}(p)=\sum_{n=1}^{N-1} \beta_{n} u\left(H_{n}\right)+\left(\beta_{N}+\beta_{H}\right) u\left(H_{N}\right), \\
u_{\text {min }}(p)=\left(\beta_{1}+\beta_{H}\right) u\left(H_{1}\right)+\sum_{n=2}^{N} \beta_{n} u\left(H_{n}\right), \\
u_{\text {arg }}(p)=\frac{u_{\max }(p)+u_{\min }(p)}{2} .
\end{gathered}
$$




\section{Case study: pavement condition assessment and utility ranking}

Pavement distresses contribute differently to the overall pavement condition depending on their importance and significance during the deterioration process. Therefore, different distresses will have diffident weights representing their importance for the whole pavement section. In this research, the relative weights of various distresses were extracted from ASTM D 6433 - 07 manual (ASTM, 2008). The data in Table 3 show the distresses and their respective weights considered for pavement condition assessment. The detailed weight analysis of pavement distresses is provided by Abu Dabous et al. (2019).

For the case study, five pavement sections were extracted from the long-term pavement performance (LTPP) program managed and operated by FHWA in the United States. Important details related to the extracted pavement sections including section area, location, distress type, and distress rating in three severity levels are listed in Table 4.

Six different assessment grades (Table 2) ranging from A (Good) to $\mathrm{F}$ (Serious) are used to assess the pavement sections. The probability of pavement sections to be assessed in each of the assessment grades is assigned using a condition risk matrix proposed by $\mathrm{Abu}$ Dabous et al. (2019). The matrix is based on five extent levels of pavement distresses as the $x$-axis and three possible severity levels as the $y$-axis. It links different extents of distresses and severity levels to six condition states implicating that the larger the extent and severity of distress, the higher the chance that the distress is severe.

The matrix (Figure 1) provides probabilistic assessments for any severity and extent values of any pavement distress. For example, at 50\% extent of distress and moderate severity level, the point of intersection is surrounded by three condition states: D (once), E (twice) and F. Hence, the distress has a double chance to be in E condition state than D and F,

Table 3. Pavement distresses and their relative weights

\begin{tabular}{lc}
\hline \multicolumn{1}{c}{ Pavement Distress } & Weight, \% \\
\hline Bleeding & 14.7 \\
Alligator (fatigue) cracking & 25.4 \\
Longitudinal cracking & 17.1 \\
Edge/random cracking & 8.6 \\
Rutting & 34.3 \\
\hline
\end{tabular}

Utility-Based

Road Maintenance

Prioritization Method

Using Pavement

Overall Condition Rating 
Table 4. Extracted pavement sections from LTPP with their area, location, and distress availability.

\begin{tabular}{|c|c|c|c|c|c|c|c|}
\hline \multirow[b]{2}{*}{ Section } & \multirow{2}{*}{$\begin{array}{c}\text { Section } \\
\text { area, } \\
\mathrm{m}^{2}\end{array}$} & \multicolumn{6}{|c|}{ Distress availability (severity level) } \\
\hline & & Ravelling & Bleeding & Potholes & $\begin{array}{l}\text { Alligator } \\
\text { cracking }\end{array}$ & $\begin{array}{l}\text { Transverse } \\
\text { cracking }\end{array}$ & $\begin{array}{l}\text { Longitudinal } \\
\text { cracking }\end{array}$ \\
\hline Section 1 & 562.4 & $\begin{array}{c}\checkmark \\
(M)\end{array}$ & $\begin{array}{c}\checkmark \\
(M)\end{array}$ & $\begin{array}{c} \\
(L)\end{array}$ & $\begin{array}{c}\checkmark \\
(L, M, H)\end{array}$ & $\begin{array}{l}\checkmark \\
(L)\end{array}$ & $\begin{array}{l}\checkmark \\
(L)\end{array}$ \\
\hline Section 2 & 577.6 & $\begin{array}{c}\checkmark \\
(\mathrm{M})\end{array}$ & $x$ & $\begin{array}{c}\checkmark \\
(H)\end{array}$ & $\begin{array}{c}\checkmark \\
(L, M, H)\end{array}$ & $\begin{array}{c}\checkmark \\
(L, M)\end{array}$ & $x$ \\
\hline Section 3 & 577.6 & $\begin{array}{c}\checkmark \\
(\mathrm{M})\end{array}$ & $x$ & $x$ & $\begin{array}{c}\checkmark \\
(L, M, H)\end{array}$ & $\begin{array}{c}\checkmark \\
(L, M)\end{array}$ & $\begin{array}{c}\checkmark \\
(L)\end{array}$ \\
\hline Section 4 & 562.4 & $\begin{array}{c}\checkmark \\
(\mathrm{M})\end{array}$ & $x$ & $\begin{array}{c}\checkmark \\
(H)\end{array}$ & $\begin{array}{c}\checkmark \\
(L, M, H)\end{array}$ & $\begin{array}{c}\checkmark \\
(L, M)\end{array}$ & $x$ \\
\hline Section 5 & 608.0 & $\begin{array}{c}\checkmark \\
(\mathrm{M})\end{array}$ & $x$ & $x$ & $\begin{array}{c}\checkmark \\
(L, M, H)\end{array}$ & $\begin{array}{c}\checkmark \\
(L, M, H)\end{array}$ & $\begin{array}{c}\checkmark \\
(L, M)\end{array}$ \\
\hline
\end{tabular}

and the initial basic assignment of the condition states would be $25 \%$ in $\mathrm{D}, 50 \%$ in $\mathrm{E}$ and $25 \%$ in $\mathrm{F}$.

The data in Table 5 show the probability assignment of pavement Section 1. The Bpa are then extracted based on the probability assignment of various distresses to one or more assessment grades (Table 6).

A detailed example showing step-by-step calculation for the overall condition assessment is provided in this section for pavement Section 1. The analytical ER equations are used for the aggregation of assessments of various distresses and overall belief calculation. The following steps demonstrate application of the analytical ER approach to bleeding distress presented in pavement Section 1. The distributed

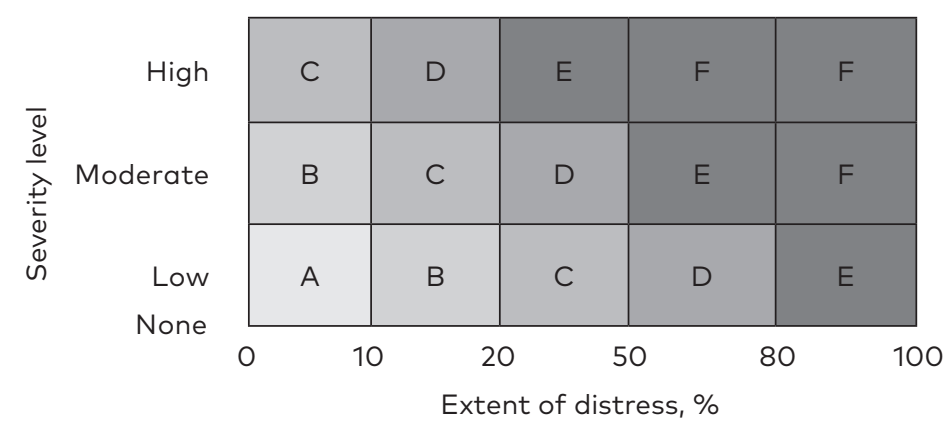

Figure 1. Pavement condition matrix based on distress severity level and extent (Abu Dabous et al. 2019) 
Table 5. Probability assignment of pavement Section 1 to various assessment grades

\begin{tabular}{lrrrrrr}
\hline \multirow{2}{*}{ Pavement distress } & \multicolumn{7}{c}{ Grade / degree of belief } \\
\cline { 2 - 7 } & \multicolumn{1}{c}{ A } & \multicolumn{1}{c}{ B } & \multicolumn{1}{c}{ C } & D & E & F \\
\hline Bleeding & 0.75 & 0.25 & 0 & 0 & 0 & 0 \\
Alligator cracking & 0 & 0 & 0.5 & 0.5 & 0 & 0 \\
Longitudinal cracking & 0.25 & 0.5 & 0.25 & 0 & 0 & 0 \\
Edge cracking & 0 & 0.5 & 0.5 & 0 & 0 & 0 \\
Rutting & 0 & 0.25 & 0.5 & 0.25 & 0 & 0 \\
\hline
\end{tabular}

Table 6. Distributed assessment of various distresses to pavement Section 1
Saleh Abu Dabous, Ghadeer Al-Khayyat, Sainab Feroz

Utility-Based

Road Maintenance

Prioritization Method Using Pavement Overall Condition Rating

\begin{tabular}{lc}
\hline \multicolumn{1}{c}{ Pavement distress } & Distributed assessment $(B p a)$ \\
\hline Bleeding & $\{(A, O .75),(B, O .25)\}$ \\
Alligator cracking & $\{(C, O .50),(D, O .50)\}$ \\
Longitudinal cracking & $\{(A, O .25),(B, O .50),(C, O .25)\}$ \\
Edge cracking & $\{(B, O .5),(C, O .5)\}$ \\
Rutting & $\{(B, O .25),(C, O .50),(D, O .25)\}$ \\
\hline
\end{tabular}

assessment as summarized in Table 5 for the considered distress is $\{(A, 0.75),(B, 0.25)\}$ with relative weight equal to $14.7 \%$, as mentioned earlier in Table 3.

Step 1: calculation of basic probability mass assigned to various assessment grades:

$$
\begin{aligned}
& m_{A, \text { Bleeding }}=m_{\text {Bleeding }}\left(H_{A}\right)=w_{\text {Bleeding }} \beta_{A, \text { Bleeding }}=0.147 \cdot 0.75=0.1103 \\
& m_{A, \text { Bleeding }}=m_{\text {Bleeding }}\left(H_{A}\right)=w_{\text {Bleeding }} \beta_{A, \text { Bleeding }}=0.147 \cdot 0.75=0.1103 .
\end{aligned}
$$

Step 2: calculation of basic probability mass assigned to the whole set $H$ :

$$
\begin{aligned}
& m_{H, \text { Bleeding }}=m_{\text {Bleeding }}(H)=1-\sum_{n=1}^{6} m_{n, \text { Bleeding }}=1-w_{\text {Bleeding }} \sum_{n=1}^{6} \beta_{n, \text { Bleeding }}= \\
& =1-(0.1103+0.0368+0+0+0+0)=0.8530 ; \\
& \bar{m}_{H, \text { Bleeding }}=\bar{m}_{\text {Bleeding }}(H)=1-w_{\text {Bleeding }}=1-0.147=0.8530 ; \\
& \tilde{m}_{H, \text { Bleeding }}=\tilde{m}_{\text {Bleeding }}(H)=w_{\text {Bleeding }}\left(1-\sum_{n=1}^{6} \beta_{n, \text { Bleeding }}\right)= \\
& =0.147[1-(0.75+0.25+0+0+0+0)]=0 ; \\
& m_{H, \text { Bleeding }}=\bar{m}_{H, \text { Bleeding }}+\tilde{m}_{H, \text { Bleeding }}=0.8530+0=0.8530 .
\end{aligned}
$$




\begin{tabular}{|c|c|c|c|c|c|c|c|c|c|}
\hline \multirow{3}{*}{ Pavement distress } & \multicolumn{6}{|c|}{ Grade / basic probability mass } & \multirow{3}{*}{$m_{H, B}$} & \multirow{3}{*}{$\bar{m}_{H, B}$} & \multirow{3}{*}{$\tilde{m}_{H, \boldsymbol{B}}$} \\
\hline & \multicolumn{6}{|c|}{$m_{n, B}$} & & & \\
\hline & A & B & C & D & E & $\mathbf{F}$ & & & \\
\hline Bleeding & 0.1103 & 0.0368 & 0 & 0 & 0 & 0 & 0.8530 & 0.8530 & 0 \\
\hline Alligator cracking & 0.0000 & 0.0000 & 0.1265 & 0.1265 & 0 & 0 & 0.7470 & 0.7470 & 0 \\
\hline Longitudinal cracking & 0.0428 & 0.0855 & 0.0428 & 0.0000 & 0 & 0 & 0.8290 & 0.8290 & 0 \\
\hline Edge cracking & 0.0000 & 0.0430 & 0.0430 & 0.0000 & 0 & 0 & 0.9140 & 0.9140 & 0 \\
\hline Rutting & 0.0000 & 0.0858 & 0.1715 & 0.0858 & 0 & 0 & 0.6570 & 0.6570 & 0 \\
\hline
\end{tabular}

Step 1 and 2 were repeated for the other distresses presented in the pavement section in the same manner applied to the bleeding distress. The data in Table 7 show the grade probability distribution for all distresses in Section 1.

Step 3: aggregation of basic probability masses for each assessment grade:

$$
\begin{aligned}
& k=\left[\sum_{n=1}^{6} \prod_{B=1}^{5}\left(m_{n, B}+\bar{m}_{H, B}+\tilde{m}_{H, B}\right)-(N-1) \prod_{B=1}^{5}\left(\bar{m}_{H, B}+\tilde{m}_{H, B}\right)\right]^{-1}= \\
& =[2.3774-(6-1)(0.3172)]^{-1}=1.2635 ; \\
& \left\{H_{n}\right\} m_{A}=k\left[\prod_{B=1}^{5}\left(m_{n, B}+\bar{m}_{H, B}+\tilde{m}_{H, B}\right)-\prod_{B=1}^{5}\left(\bar{m}_{H, B}+\tilde{m}_{H, B}\right)\right]= \\
& =1.2635(0.3767-0.3172)=0.0751 ; \\
& \left\{H_{n}\right\} m_{B}=k\left[\prod_{B=1}^{5}\left(m_{n, B}+\bar{m}_{H, B}+\tilde{m}_{H, B}\right)-\prod_{B=1}^{5}\left(\bar{m}_{H, B}+\tilde{m}_{H, B}\right)\right]= \\
& =1.2635(0.4320-0.3172)=0.1451 ; \\
& \left\{H_{n}\right\} m_{C}=k\left[\prod_{B=1}^{5}\left(m_{n, B}+\bar{m}_{H, B}+\tilde{m}_{H, B}\right)-\prod_{B=1}^{5}\left(\bar{m}_{H, B}+\tilde{m}_{H, B}\right)\right]= \\
& =1.2635(0.5150-0.3172)=0.2499 ; \\
& \left\{H_{n}\right\} m_{D}=k\left[\prod_{B=1}^{5}\left(m_{n, B}+\bar{m}_{H, B}+\tilde{m}_{H, B}\right)-\prod_{B=1}^{5}\left(\bar{m}_{H, B}+\tilde{m}_{H, B}\right)\right]= \\
& =1.2635(0.4193-0.3172)=0.1290 ;
\end{aligned}
$$




$$
\begin{aligned}
& \left\{H_{n}\right\} m_{E}=k\left[\prod_{B=1}^{5}\left(m_{n, B}+\bar{m}_{H, B}+\tilde{m}_{H, B}\right)-\prod_{B=1}^{5}\left(\bar{m}_{H, B}+\tilde{m}_{H, B}\right)\right]= \\
& =1.2635(0.3172-0.3172)=0 ; \\
& \left\{H_{n}\right\} m_{F}=k\left[\prod_{B=1}^{5}\left(m_{n, B}+\bar{m}_{H, B}+\tilde{m}_{H, B}\right)-\prod_{B=1}^{5}\left(\bar{m}_{H, B}+\tilde{m}_{H, B}\right)\right]= \\
& =1.2635(0.3172-0.3172)=0 ; \\
& \{H\}: \tilde{m}_{H}=k\left[\prod_{B=1}^{5}\left(\bar{m}_{H, B}+\tilde{m}_{H, B}\right)-\prod_{B=1}^{5} \bar{m}_{H, B}\right]= \\
& =1.2635(0.3172-0.3172)=0 ; \\
& \{H\} \bar{m}_{H}=k\left(\prod_{B=1}^{5} \bar{m}_{H, B}\right)=1.2635 \cdot 0.3172=0.4008 .
\end{aligned}
$$

Step 4: normalization of aggregated probability masses into overall belief degrees:

$$
\begin{aligned}
& \left\{H_{n}\right\}: \beta_{A}=\frac{m_{A}}{1-\bar{m}_{H}}=\frac{0.0751}{1-0.4008}=0.1254 ; \\
& \left\{H_{n}\right\}: \beta_{B}=\frac{m_{B}}{1-\bar{m}_{H}}=\frac{0.1451}{1-0.4008}=0.2422 ; \\
& \left\{H_{n}\right\}: \beta_{C}=\frac{m_{C}}{1-\bar{m}_{H}}=\frac{0.2499}{1-0.4008}=0.4171 ; \\
& \left\{H_{n}\right\}: \beta_{D}=\frac{m_{D}}{1-\bar{m}_{H}}=\frac{0.1290}{1-0.4008}=0.2154 ; \\
& \left\{H_{n}\right\}: \beta_{E}=\frac{m_{E}}{1-\bar{m}_{H}}=\frac{0}{1-0.4008}=0 ; \\
& \left\{H_{n}\right\}: \beta_{F}=\frac{m_{F}}{1-\bar{m}_{H}}=\frac{0}{1-0.4008}=0 ; \\
& \{H\}: \beta_{H}=\frac{\tilde{m}_{H}}{1-\bar{m}_{H}}=\frac{0}{1-0.4008}=0 .
\end{aligned}
$$

Pavement Section 1 was assessed as belonging to grades $A, B, C$, and D with $12.54 \%, 24.22 \%, 41.71 \%$, and $21.54 \%$ probabilities, respectively, as shown in Figure 2 below. The overall condition assessment of the pavement section was mainly as being in grade $C$ (Fair condition). The overall condition of the other four sections were obtained following the same steps.

Five pavement sections were considered within the case study to implement the utility equations for maintenance prioritization based on sections condition assessment. Condition assessment of various pavement sections was obtained utilizing an evidential reasoning
Utility-Based

Road Maintenance

Prioritization Method Using Pavement Overall Condition Rating 


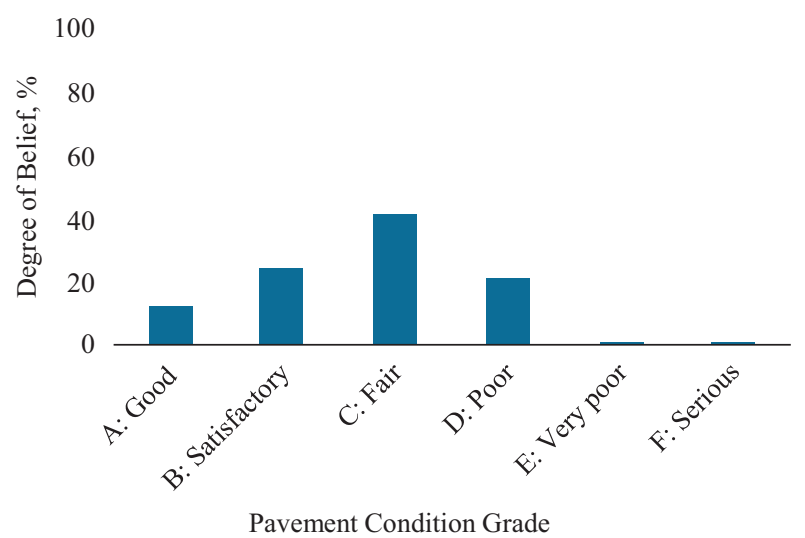

Figure 2. Overall condition assessment of pavement Section 1

approach. An aggregated distributed assessment for each pavement section was produced as a degree of belief assigned to each assessment grade in addition to ignorance value if the assessment of the pavement section was not complete. The overall degrees of belief and ignorance of the five pavement sections are shown in Table 8.

Based on the assessment data, Sections 1, 3 and 4 had no ignorance and the information related to their overall condition assessment was complete. On the other hand, pavement Sections 2 and 5 include some ignorance due to incompleteness in their original assessment information. According to the results shown in Table 8, pavement Section 1 had $42 \%$ chance of being in grade $C$, which is the fair condition rating. However, condition of Section 2 can be between grade $\mathrm{C}$ and $\mathrm{D}$ but closer to grade $\mathrm{D}$, which indicates poor condition. As such, Section 3 has close chances of being assessed as being in grade A, B, and C with $32 \%, 33 \%$, and $26 \%$, respectively with the highest probability to be assigned to

Table 8. Aggregated distributed assessments in terms of degrees of belief for the five pavement sections

\begin{tabular}{cccccccc}
\hline \multirow{2}{*}{ Pavement Section } & \multicolumn{7}{c}{ Degrees of belief, \% } \\
\cline { 2 - 8 } & A & B & C & D & E & F & Ignorance \\
\hline Section 1 & 13 & 24 & 42 & 21 & 0 & 0 & 0 \\
Section 2 & 0 & 3 & 31 & 49 & 14 & 0 & 3 \\
Section 3 & 32 & 33 & 26 & 9 & 0 & 0 & 0 \\
Section 4 & 9 & 36 & 39 & 13 & 3 & 0 & 0 \\
Section 5 & 0 & 0 & 14 & 38 & 35 & 5 & 7 \\
\hline
\end{tabular}




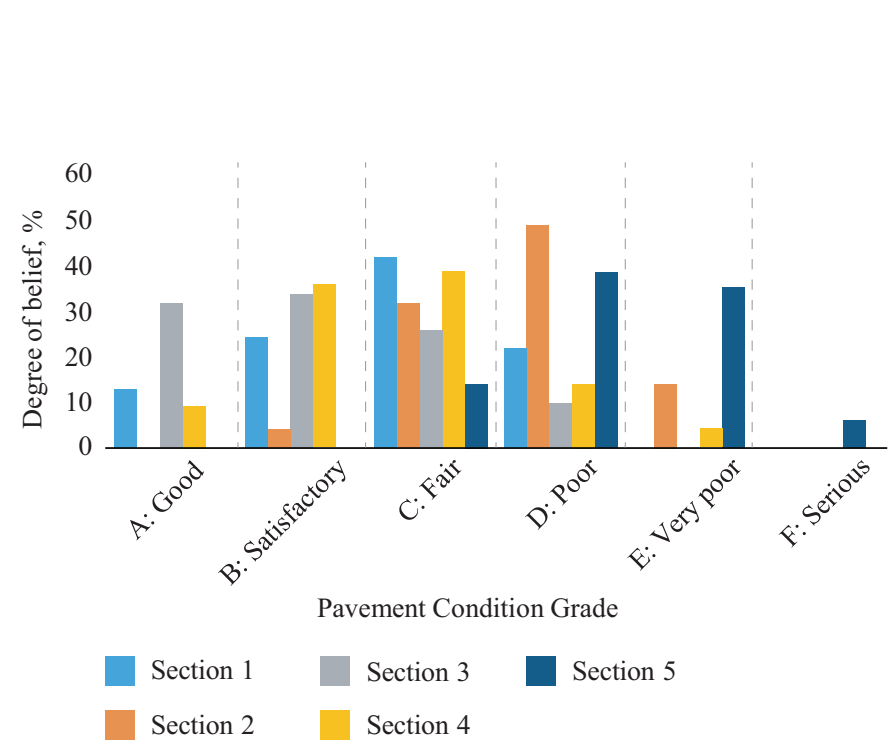

Figure 3. Overall condition assessments of the five pavement sections

grade B, which represent satisfactory condition. For Section 4, pavement condition can be considered between grade $\mathrm{B}$ and $\mathrm{C}$ but closer to grade $C$ (fair condition). The overall condition of Section 5 is between grade $\mathrm{D}$ and $\mathrm{E}$ with a higher belief attached to grade D (poor condition). The overall conditions of the five pavement sections are shown in Figure 3. Based on their overall condition assessment, it is shown that pavement Section 3 had the best condition assessment while Section 5 got the worst assessment. Such conclusion will be confirmed after applying utility equations for pavements ranking purposes.

As introduced previously, utility approach is utilized here to rank the five pavement sections for maintenance prioritization based on their overall condition assessment. Utility technique consists of three equations for calculating maximum utility, minimum utility, and average utility (Eqs. 2-4). A numerical example on how to calculate the utilities of a pavement section was conducted on pavement Section 2. The degrees of belief in each assessment grade and the ignorance in case of pavement Section 2 (Table 8) in addition to the utilities of various assessment grades (Table 2) were used to calculate the maximum and minimum utilities of the pavement section. The following three steps show calculation of utilities of pavement Section $2\left(p_{2}\right)$ :

Step 1 (maximum utility):

$$
\begin{aligned}
& u_{\max }\left(p_{2}\right)=\sum_{n=1}^{5} \beta_{n} u\left(H_{n}\right)+\left(\beta_{6}+\beta_{H}\right) u\left(H_{6}\right)= \\
& =(0 \cdot 0+0.0339 \cdot 0.1+0.3142 \cdot 0.3+0.4854 \cdot 0.5+0.1362 \cdot 0.7) \\
& +(0+0.03038) \cdot 0.9=0.43569+0.027342=0.46303
\end{aligned}
$$


Step 2 (minimum utility):

$$
\begin{aligned}
& u_{\min }\left(p_{2}\right)=\left(\beta_{1}+\beta_{H}\right) u\left(H_{1}\right)+\sum_{n=2}^{6} \beta_{n} u\left(H_{n}\right)= \\
& =[(0+0.03038) \cdot 0+0.0339 \cdot 0.1] \\
& +[(0+0.03038) \cdot 0+0.3142 \cdot 0.3][(0+0.03038) \cdot 0+0.4854 \cdot 0.5] \\
& +[(0+0.03038) \cdot 0+0.1362 \cdot 0.7]+[(0+0.03038) \cdot 0+0 \cdot 0.9]= \\
& =0.00339+0.09426+0.2427+0.09534+0=0.43569 .
\end{aligned}
$$

Step 3 (average utility):

$$
\frac{u_{\max }\left(p_{2}\right)+u_{\min }\left(p_{2}\right)}{2}=\frac{0.46303+0.43569}{2}=0.44936 \text {. }
$$

The data in Table 9 present the ranking results based on the utility approach. Due to incompleteness in the assessment of pavement Sections 2 and 5, their utilities are expressed as intervals ranging between the minimum and maximum values. On the other hand, Sections 1, 3, and 4 had their assessment complete and as a result one precise utility was estimated for each section. The ranking results based on the utility values can be used to prioritize pavement sections in terms of maintenance need. Section 5 was ranked as the worst section compared to the others which needs to be considered first for maintenance and rehabilitation. In contrast, Section 3 was ranked as the best section which does not require immediate attention. The ranking results obtained using the proposed ranking method are consistent with the maintenance priority remarks provided by the inspectors for these sections. The remarks indicated that Sections 1 and 2 had high maintenance priority and Sections 3, 4 and 5 were ascribed low priority. The proposed method has a major advantage over the subjective assessments submitted by inspectors, since this method provides quantitative priority as utility values for different sections. In addition,

Table 9. Maximum, minimum, and average utilities for the five pavement sections with their ranks

\begin{tabular}{ccccc}
\hline Pavement section & Maximum utility & Minimum utility & Average utility & Section rank \\
\hline Section 1 & 0.2570 & 0.2570 & 0.2570 & 3 \\
Section 2 & 0.4356 & 0.4630 & 0.4493 & 2 \\
Section 3 & 0.1560 & 0.1560 & 0.1560 & 5 (best) \\
Section 4 & 0.2434 & 0.2434 & 0.2434 & 4 \\
Section 5 & 0.5261 & 0.5956 & 0.5608 & 1 (worst) \\
\hline
\end{tabular}


the utility values can be advanced further to link to the appropriate maintenance intervention based on the utility and condition rating of the sections.

\section{Conclusion}

In this paper, the utility approach was utilized for pavement maintenance prioritization. Pavement condition assessment was performed by an inspector and the final degrees of belief concerning various assessment grades were provided. The case study considering five pavement sections was used to demonstrate the utility approach. Average utilities were assessed for the pavement sections ranking purposes based on the overall condition assessment. Due to pavement deterioration with time, new condition ratings are expected with new inspection cycles. However, when new condition rating of a pavement section is produced, the new rating will be reflected on the distributed assessment of the pavement section. Based on the five sections considered in this study, pavement Section 5 was ranked in the first place to be considered for maintenance activities. At the same time, Section 3 had the best condition assessment compared to other sections and therefore it got the last rank in terms of maintenance prioritization, which means intervention is not urgent. Based on the case study, the method had proven to be practical and can be used in performing the needed maintenance priority ranking from the available inspection results. The case study is based on the data extracted from the LTPP database. The method is expected to be applicable in other countries and under different conditions. Further work can validate implementation of the method with the data on different roads segments and further evaluate the method performance. Departments of transportation can use the proposed method to prioritize pavement sections for maintenance and to allocate the available budget to the sections with the highest utility. Further research on the issues discussed in the current work can focus on limited budget allocation to high priority pavement sections through optimization techniques.

\section{Acknowledgements}

The authors would like to thank the Sustainable Civil Infrastructure Research Group and Research Institute of Sciences and Engineering (RISE) at University of Sharjah for supporting this research.
Utility-Based

Road Maintenance

Prioritization Method

Using Pavement

Overall Condition Rating 


\section{REFERENCES}

ASTM. (2008). Standard Practice for Roads and Parking Lots Pavement Condition Index Surveys (D 6433 - 07).

Abu Dabous, S. (2017). Assessing transition probability of bridge deterioration using Dempster - Shafer theory of evidence. Bridge Structures, 12(3-4), 97-106. https://doi.org/10.3233/BRS-170105

Abu Dabous, S. \& Al-Khayyat, G. (2018). A Flexible Bridge Rating Method Based on Analytical Evidential Reasoning and Monte Carlo Simulation. Advances in Civil Engineering, 2018, 1-13. https://doi.org/10.1155/2018/1290632

Abu Dabous, S., Zeiada, W., Al-Ruzouq, R., Hamad, K., \& Al-Khayyat, G. (2019). Distress-based evidential reasoning method for pavement infrastructure condition assessment and rating. International Journal of Pavement Engineering, 1-12. https://doi.org/10.1080/10298436.2019.1622012

Babashamsi, P., Golzadfar, A., Yusoff, N. I. M., Ceylan, H., \& Nor, N. G. M. (2016). Integrated fuzzy analytic hierarchy process and VIKOR method in the prioritization of pavement maintenance activities. International Journal of Pavement Research and Technology, 9(2), 112-120. https://doi.org/10.1016/j.ijprt.2016.03.002

Chang, J. R. (2013). Particle Swarm Optimization Method for Optimal Prioritization of Pavement Sections for Maintenance and Rehabilitation Activities. Applied Mechanics and Materials, 343, 43-49. https://doi.org/10.4028/www.scientific.net/AMM.343.43

Chouinard, B. L. E., Andersen, G. R., \& Torrey, V. H. (1996). Ranking Models Used for Condition Assessment of Civil Infrastructure Systems. Journal of Infrastructure Systems, 2(1), 23-29.

https://doi.org/10.1061/(asce)1076-0342(1996)2:1(23)

Dempster, A. (1968). A generalisation of Bayesian inference. Journal of Royal Statistical Society, Series B, 30(2), 205-247.

El-rayes, K., \& Kandil, A. (2005). Time-Cost-Quality Trade-Off Analysis for Highway Construction. Journal of Construction Engineering and Managementment, 131(4), 477-486. https://doi.org/10.1061/(asce)0733-9364(2005)131:4(477)

Fwa, T. F., \& Chan, W. T. (1993). Priority Rating Of Highway Maintenance Needs By Neural Networks. Journal of Transportation Engineering, 119(3), 419-432. https://doi.org/10.1061/(asce)0733-947x(1993)119:3(419)

Fwa, T. F., Chan, W. T., \& Hoque, K. Z. (1998). Analysis of Pavement Management Activities Programming by Genetic Algorithms. Transportation Research Record, 1643, 1-6. https://doi.org/10.3141/1643-01

Gao, L., Xie, C., \& Zhang, Z. (2012). Network-Level Road Pavement Maintenance and Rehabilitation Scheduling for Optimal Performance Improvement and Budget Utilization. Computer-Aided Civil and Infrastructure Engineering, 27(4), 276-287. https://doi.org/10.1111/j.1467-8667.2011.00733.x

Haas, R., Hudson, W. R., \& Zaniewski, J. (1994). Modern pavement management. Malabar, FL: Krieger. 
Hudson, W. R., Haas, R., \& Pedigo, R. D. (1979). Pavement management system development. Washington: Transportation Research Board.

Moazami, D., Behbahani, H., \& Muniandy, R. (2011). Pavement rehabilitation and maintenance prioritization of urban roads using fuzzy logic. Expert Systems With Applications, 38(10), 12869-12879. https://doi.org/10.1016/j.eswa.2011.04.079

Ouma, Y. O., Opudo, J., \& Nyambenya, S. (2015). Comparison of Fuzzy AHP and Fuzzy TOPSIS for Road Pavement Maintenance Prioritization: Methodological Exposition and Case Study. Advances in Civil Engineering, 2015, 1-17. https://doi.org/10.1155/2015/140189

Reddy, B. B., \& Veeraragavan, A. (2001). Priority ranking model for managing flexible pavements at network level. Journal of Indian Road Congress, 62, 379-394.

Shafer, G. (1976). A Mathematical Theory of Evidence. Princeton, NJ, USA: Princeton University Press.

Shah, Y. U., Jain, S. S., \& Parida, M. (2014). Evaluation of prioritization methods for effective pavement maintenance of urban roads. International Journal of Pavement Engineering, 15(3), 238-250. https://doi.org/10.1080/10298436.2012.657798

Sun, L., \& Gu, W. (2011). Pavement Condition Assessment Using Fuzzy Logic Theory and Analytic Hierarchy Process. Journal of Transportation Engineering, 137(9), 648-655. https://doi.org/10.1061/(ASCE)TE.1943-5436.0000239

Tayebi, N. R., Moghadasnejhad, F., \& Hassani, A. (2010). Analysis of pavement management activities programming by particle swarm optimization. International Journal on Communication.

Temesgen Girmay. (2016). Asphalt Road Pavement Rehabilitation and Maintenance: Case Study in Addis Ababa City Roads Authority.

The Ohio Department of Transportation and U.S. Department of Transportation, F. H. A. (1998). Review of PCR Methodology.

Torres-machí, C., Chamorro, A., Videla, C., Pellicer, E., \& Yepes, V. (2014). An Iterative Approach for the Optimization of Pavement Maintenance Management at the Network Level. The Scientific World Journal, 2014, 1-11. https://doi.org/10.1155/2014/524329

Wang, Y. M., \& Elhag, T. M. S. (2008). Evidential reasoning approach for bridge condition assessment. Expert Systems with Applications, 34(1), 689-699. https://doi.org/10.1016/j.eswa.2006.10.006

Wang, Y., Yang, J.-B., \& Xu, D.-L. (2006). Environmental impact assessment using the evidential reasoning approach. European Journal of Operational Research, 174(3), 1885-1913. https://doi.org/10.1016/j.ejor.2004.09.059

Xiong, Y., \& Kuang, Y. P. (2007). Time-cost trade-off of construction project based on ant colony algorithm. System Engineering Theory and Practice, 27, 105-111.

Yang, J.-B., \& Xu, D.-L. (2002). On the evidential reasoning algorithm for multiple attribute decision analysis under uncertainty. IEEE Transactions on Systems, Man, and Cybernetics - Part A: Systems and Humans, 32(3), 289-304.

https://doi.org/10.1109/TSMCA.2002.802746 
THE BALTIC JOURNAL OF ROAD AND BRIDGE ENGINEERING 2020/15(1)

Zheng, D. X. M., \& Ng, S. T. (2005). Stochastic Time-Cost Optimization Model Incorporating Fuzzy Sets Theory and Nonreplaceable Front. Journal of Construction Engineering and Management, 131(2), 176-186. https://doi.org/10.1061/(asce)0733-9364(2005)131:2(176)

Zheng, D. X. M., Ng, S. T., \& Kumaraswamy, M. M. (2004). Applying a Genetic Algorithm-Based Multiobjective Approach for Time-Cost Optimization. Journal of Construction Engineering and Management, 130(2), 168-176. https://doi.org/10.1061/(ASCE)0733-9364(2004)130:2(168) 